\title{
Ethnic differences in overweight and obesity and the influence of acculturation on immigrant bodyweight: evidence from a national sample of Australian adults
}

\author{
Karen Menigoz ${ }^{1 *}$, Andrea Nathan ${ }^{1}$ and Gavin Turrell ${ }^{1,2}$
}

\begin{abstract}
Background: Despite growing international migration and documented ethnic differences in overweight and obesity in developed countries, no research has described the epidemiology of immigrant overweight and obesity at a national level in Australia, a country where immigrants comprise $28.1 \%$ of the population. The aim of this study was to examine ethnic differences in body mass index (BMI) and overweight/obesity in Australia and the influence of acculturation on bodyweight among Australian immigrants.

Methods: Data from the national Household Income and Labour Dynamics in Australia (HILDA) survey were used to examine mean BMl and odds of overweight/obesity comparing immigrants $(n=2$ 997) with Australian born $(n=13$ 047). Among immigrants, acculturation differences were examined by length of residence in Australia and age at migration. Data were modelled in a staged approach using multilevel linear and logistic regression, controlling for demographic and socioeconomic variables.

Results: Relative to Australian born, men from North Africa/Middle East and Oceania regions had significantly higher BMIs, and men from North West Europe, North East Asia and Southern and Central Asia had significantly lower BMls. Among women, the majority of foreign born groups had significantly lower BMls compared with Australian born. Male and female immigrants living in Australia for 15 years or more had significantly higher BMls and increased odds of being overweight/obese respectively, compared with immigrants living in Australia for less than 5 years. Male immigrants arriving as adolescents were twice more likely to be overweight/obese and had significantly higher BMls than immigrants who arrived as adults. Male and female immigrants who arrived as children ( $\leq 11$ years) had significantly higher odds of adult overweight/obesity and BMls.

Conclusions: This study provides evidence of ethnic differences in overweight and obesity in Australia with male immigrants from North Africa/Middle East and Oceania regions being particularly vulnerable. In addition, this study suggests that greater acculturation may negatively impact immigrant bodyweight and recently arrived immigrants as well as those who arrive as children or adolescents may benefit from obesity prevention intervention. Public health policy targeted at and tailored to these immigrant cohorts will assist in the multi-pronged approach required to address the obesity epidemic.
\end{abstract}

Keywords: Obesity, BMI, Bodyweight, Ethnicity, Immigrant, Minority, Acculturation, Prevention, Inequality, Australia

Abbreviations: BMI, Body mass index; Crl, Credible interval; HILDA, Household, income and labour dynamics in Australia; MCMC, Markov chain Monte Carlo; OR, Odds ratio; WHO, World Health Organisation

\footnotetext{
* Correspondence: karen.menigoz@hdr.qut.edu.au

${ }^{1}$ School of Public Health and Social Work, Queensland University of

Technology (QUT), Victoria Park Road, Kelvin Grove, QLD 4059, Australia

Full list of author information is available at the end of the article
} 


\section{Background}

Obesity is a significant global health challenge impacting both developing and developed countries [1]. Worldwide, international migration has increased $41 \%$ from 2000 to 2015, with over 244 million people now living in a country other than where they were born [2]. The prevalence of overweight and obesity is ethnically [3-6] as well as socioeconomically patterned [7-10] and understanding the nature of these relationships is important in designing effective obesity prevention policy.

Ethnicity and bodyweight research is dominated by studies from the United States and Europe which demonstrate stark, multi-generational inequalities in overweight and obesity among some ethnic minority groups $[3,4,11-15]$. Few studies however have focused on the Asia Pacific region and no published studies have defined ethnic differences in bodyweight in a national sample of Australian adults. Australia has high rates of overweight and obesity (70.3\% of men and $56.2 \%$ of women) [16] and a particularly high immigrant population with $28.1 \%$ of the population born overseas [17] (in contrast for example, to the United States which has $12.5 \%$ born overseas [18]). It is somewhat surprising therefore, that epidemiological studies of ethnic difference in bodyweight in Australia have focused largely on children [19-22] and the three known studies that focused on adults [23-25] have a number of substantive and methodological limitations. In particular, previous Australian studies have been based on single State surveys, were not inclusive of all ethnic groups, two studies did not address expected gender differences [23, 24] and two studies were limited to older adults $[23,25]$.

Alongside ethnic differences in bodyweight, a related body of research has examined the influence of acculturation on immigrant bodyweight. Acculturation is defined as a change in cultural patterns arising from exposure to the host country's lifestyle, environment and culture [26, 27]. Studies primarily from the United States and United Kingdom have consistently shown that upon arrival, immigrants have lower BMI, overweight and obesity relative to their host-country born counterparts $[5,12$, 28-31] however longer residence has been shown to be associated with higher BMI [28, 30, 32, 33] - often attributed to acculturation [32, 33]. Acculturation can be assessed with scale measures (typically measuring language, use of media in the host country, values, lifestyle, attitudes and ethnic social relations and networks), as well as via temporal measures such as length of residence in the host country and age at arrival [32, 34]. While scale measures more sensitively measure social structural and cultural changes, temporal measures are more readily available and commonly used in population immigrant health research [32, 34]. Length of residence is thought to influence immigrant overweight and obesity through behavioural change such as adoption of unhealthy dietary habits [35]; contextual effects, such as ethnic social network [5] and neighbourhood effects [36]; and a range of individual differences - in household income, English proficiency, acculturative stress, experiences of discrimination [37] and education, gender and racial/ethnic group [28]. Age at arrival may influence adult obesity risk due to the different adaptive capabilities of children vs adults [38], English language proficiency [39], wage earning potential [39], and the level of acculturation to behaviours such as physical activity, diet and smoking [40]. While this topic has received some attention in the Australian context [24, 25, 35], there are no known studies to date, which have examined at a national level, whether acculturation and obesity relationships hold true in Australia's unique immigration history and immigration policy environment.

The aim of this present study therefore, is to present for the first time, national-level findings on the genderspecific ethnic differences in BMI and overweight/obesity in Australian adults and the influence of acculturation on bodyweight among immigrants to Australia.

\section{Methods}

\section{Study design and sample}

This paper uses Wave 11 (2011) data from the Household Income and Labour Dynamics in Australia (HILDA) survey. HILDA is a national, household-based longitudinal survey about life in Australia that includes a range of ethnicity and migration related variables and information on economic, social and demographic characteristics. The HILDA methodology is described in detail elsewhere [41]. Briefly, the scope and coverage of the survey are Australian households (and usual residents) in private dwellings, excluding very remote and sparsely populated areas [41]. The panel in wave 1 of the survey consisted of 7682 responding households and 19914 individuals. The sample was topped up in wave 11 with an additional 2153 responding households. The selection method for the top-up sample was similar to the original sample methodology [42]. The survey research team have examined the issue of cross-sectional representativeness and found that combining the main sample with the top up sample served to improve the quality of the cross-sectional estimates (compared to just using the main sample), particularly for estimates of country of birth and year of arrival [43]. The survey researchers also found that the combined sample resulted in estimates which more closely reflected data benchmarked from the Australian Bureau of Statistics Labour Force Survey [43]. The majority of wave 11 interviews were conducted during the period August to November, 2011. Data were collected using personal interviews with each member of the household aged $\geq 15$ years, followed by a self- 
completion questionnaire which included questions on lifestyle and health habits. In 2011, 10440 households were included in the study with $64.9 \%$ of these being fully responding households: this resulted in a sample of 17612 responding individuals.

\section{Measures}

\section{Anthropometric measurements}

Two common indicators of population weight, mean BMI and prevalence of overweight/obesity were used in this study. Weight and height were self-reported and BMI was calculated as weight in kilograms divided by the square of height in metres and outliers removed [44]. The dichotomous variable for overweight/obesity (or not) was derived as per WHO cut offs (BMI $>25 \mathrm{~kg} \mathrm{~m}^{-2}$ ) [45]. Overweight/obesity as a combined category is clinically relevant due to the established health consequences of exceeding a body mass index of $25 \mathrm{~kg} \mathrm{~m}^{-2}$ (see $\mathrm{Ng}$ et al. [1] for an overview). It is also a policy-relevant categorisation reflecting international obesity reduction targets and indicators [45].

\section{Ethnicity}

The ethnicity variable used in this study was Country of birth (sometimes referred to as Nativity), categorised into regions using the Standard Australian Classification of Countries (based on geographic proximity and similarities in economic, social and political characteristics) [46].

\section{Acculturation}

There were two acculturation variables. Length of residence in Australia was calculated by subtracting the year the person first came to Australia to live from the year of the survey; and Age at arrival, calculated by subtracting the year of birth from the year the person first came to Australia to live. Consistent with previous research $[33,40]$, both variables were transformed into categorical variables for the analysis (see Table 1 for definitions).

\section{Controls}

Six demographic and socioeconomic variables were included in the models as controls to address potential sources of confounding as identified in the literature [5, $7,9,28]$. Variables were categorised as shown in Table 1 and included age (date of birth), highest educational qualification, occupation and annual household income, with data collected through interviewer-administered questionnaires [41]. Neighbourhood disadvantage was derived by the data provider from a ranking based on the Australian Bureau of Statistics' methods of compiling a range of indicators of socio-economic disadvantage into a single 'SEIFA' (Socio-Economic Indexes for Areas) index [47]. For this study the SEIFA 2011 Decile of Index of Relative Socio-economic Disadvantage (IRSD) was used to calculate quintiles of neighbourhood disadvantage. Area remoteness was derived by the dataprovider and based on the Australian Standard Geographical Classification (ASGC) [48]. Remoteness was included as a control variable as it is an element of disadvantage that has been linked to obesity in Australia $[49,50]$.

\section{Analysis}

The analysis comprised two stages: the first examined the relationship between ethnicity (country of birth) and bodyweight; and the second stage examined acculturation (length of stay and age at arrival) and bodyweight.

\section{Ethnicity and bodyweight}

Those who were aged $<18$ years or were pregnant in the last year were removed from the sample $(n=1751)$ as out of scope for this study. Those who had no selfcompleted questionnaire, had missing or implausible BMI data or missing data for the predictor variables ( $n$ $=2$ 814) were also excluded from the analysis: of these, predictors for non-inclusion were younger age (18-24 and $25-34$ years $)(p<0.001)$ and those born in Oceania $(p=0.041)$, Southern \& Eastern Europe $(p<0.001)$, North Africa \& Middle East $(p<0.001)$ and South East Asia $(p=0.001)$. The final analytic sample included 13 047 adults (6 216 men and 6831 women). We examined the relationship between ethnicity and bodyweight using a staged modelling approach and stratifying by gender. The staged approach included a base model (model 1) with only country of birth and subsequently adjusted for age (model 2) and adjusted for socioeconomic variables and area remoteness (model 3). The reference group was Australian born. Multilevel linear and logistic regression techniques were selected due to the multi-level structure of the data and to account for clustering at the individual, household, neighbourhood and area levels. Regression analyses were used to examine associations between the outcome variables (BMI, overweight/obesity) and the predictor variables. We tested for an interaction between ethnicity and sex on BMI. The parameters for the multilevel logistic models were estimated using Markov Chain Monte Carlo (MCMC) simulation [51]. Results are presented as odds ratios and their $95 \%$ credible intervals (CrI). All models were run with sufficient iterations to meet the minimum estimation requirements. The statistical analyses were performed using STATA 12 and MLwiN [52].

\section{Acculturation and bodyweight}

For the second stage of the analysis, we took the analytic sample from the first stage and excluded those born in Australia, resulting in a sample of 2997 foreign-born adults (1 457 men and 1540 women). The modelling approach was the same as previous, with the addition of a 
Table 1 Socio-demographic and bodyweight characteristics of men and women: ethnicity and bodyweight analytic sample $(n=13$ 047)

\begin{tabular}{|c|c|c|c|c|c|c|}
\hline & \multicolumn{3}{|c|}{$\begin{array}{l}\text { Men } \\
(n=6216,47.6 \%) \\
27.1(5.0) \text { Mean BMI (SD) } \\
\text { 65.2\%Owt/Obese }\end{array}$} & \multicolumn{3}{|c|}{$\begin{array}{l}\text { Women } \\
(n=6 \text { 831, 52.4 \%) } 26.6 \text { (6.3) } \\
\text { Mean BMI (SD) } \\
\text { 52.8\%Owt/Obese }\end{array}$} \\
\hline & $\%$ & Mean BMI (SD) & $\%$ Owt/Obese & $\%$ & Mean BMI (SD) & \%Owt/Obese \\
\hline \multicolumn{7}{|l|}{ Country of birth } \\
\hline Australian born & 76.5 & $27.1(4.9)$ & 65.3 & 77.4 & $26.8(6.4)$ & 54.2 \\
\hline Oceania (excluding Australia) & 3.3 & $28.3(5.5)$ & 71.6 & 2.6 & $27.0(5.7)$ & 58.5 \\
\hline North-West Europe & 9.5 & $26.9(4.4)$ & 67.3 & 8.4 & $26.6(5.9)$ & 53.1 \\
\hline Southern \& Eastern Europe & 2.6 & $27.7(4.3)$ & 74.7 & 2.5 & $27.5(5.7)$ & 64.5 \\
\hline North Africa \& The Middle East & 1.0 & $28.8(8.5)$ & 68.8 & 0.7 & $28.0(6.2)$ & 62.2 \\
\hline South-East Asia & 1.7 & $26.3(5.6)$ & 53.3 & 2.7 & $24.7(6.2)$ & 35.3 \\
\hline North-East Asia & 1.1 & $25.2(5.7)$ & 39.4 & 1.8 & $21.5(3.0)$ & 11.6 \\
\hline Southern \& Central Asia & 1.9 & $25.7(6.1)$ & 51.7 & 1.6 & $25.0(6.4)$ & 42.6 \\
\hline Americas & 1.1 & $28.2(5.5)$ & 71.4 & 1.4 & $25.3(6.3)$ & 43.3 \\
\hline Sub-Saharan Africa & 1.2 & $26.0(3.5)$ & 58.9 & 1.0 & $24.5(5.1)$ & 35.7 \\
\hline \multicolumn{7}{|l|}{ Age } \\
\hline 18-24 years & 13.2 & $24.8(4.7)$ & 40.3 & 12.4 & $23.7(5.2)$ & 26.7 \\
\hline $25-34$ years & 14.4 & $26.4(4.5)$ & 58.8 & 13.8 & $25.4(6.3)$ & 41.8 \\
\hline $35-44$ years & 16.8 & $27.6(5.1)$ & 68.3 & 17.7 & $27.2(6.6)$ & 55.1 \\
\hline $45-54$ years & 20.3 & $27.8(4.9)$ & 73.3 & 19.7 & $27.2(6.5)$ & 56.1 \\
\hline $55-64$ years & 16.6 & $28.3(5.2)$ & 74.2 & 17.3 & $28.0(6.3)$ & 63.5 \\
\hline $65-74$ years & 11.4 & $27.5(4.8)$ & 72.3 & 11.0 & $27.8(6.0)$ & 64.4 \\
\hline$>75$ years & 7.2 & $26.2(4.4)$ & 61.3 & 8.1 & $26.1(5.5)$ & 54.7 \\
\hline \multicolumn{7}{|l|}{ Remoteness } \\
\hline Major City & 63.4 & $26.9(4.9)$ & 63.3 & 63.8 & $26.3(6.2)$ & 50.0 \\
\hline Inner Regional Australia & 24.1 & $27.3(5.0)$ & 67.4 & 24.7 & $27.1(6.2)$ & 57.3 \\
\hline Outer Regional Australia & 10.9 & $27.6(5.3)$ & 69.4 & 9.9 & $27.6(7.0)$ & 58.6 \\
\hline Remote and Very Remote Australia & 1.6 & $28.5(4.6)$ & 78.6 & 1.6 & $27.5(6.4)$ & 57.8 \\
\hline \multicolumn{7}{|l|}{ Highest attained education level } \\
\hline Bachelor + & 23.5 & $26.7(4.6)$ & 63.5 & 26.1 & $25.6(5.6)$ & 45.4 \\
\hline Diploma & 9.4 & $27.3(4.5)$ & 68.0 & 9.5 & $26.4(6.4)$ & 51.2 \\
\hline Certificate (trade/business) & 28.6 & $27.7(4.9)$ & 71.2 & 16.2 & $27.3(6.5)$ & 57.7 \\
\hline School - Year 12 and below & 38.4 & $26.9(5.3)$ & 61.0 & 48.2 & $27.0(6.5)$ & 55.4 \\
\hline \multicolumn{7}{|l|}{ Occupation } \\
\hline Managers and professionals & 27.7 & $27.1(4.3)$ & 68.3 & 23 & $26.0(5.6)$ & 47.1 \\
\hline White Collar & 13.6 & $27.0(5.2)$ & 60.7 & 30.8 & $26.3(6.3)$ & 50.2 \\
\hline Blue Collar & 29.8 & $27.2(4.9)$ & 65.1 & 6.9 & $26.8(6.8)$ & 52.1 \\
\hline Unemp/Not in Labour Force & 28.8 & $27.0(5.4)$ & 64.4 & 39.3 & $27.2(6.6)$ & 58.2 \\
\hline \multicolumn{7}{|l|}{ Household Income } \\
\hline$>\$ 130,000 \mathrm{k}$ per annum & 19.4 & $27.0(4.6)$ & 64.4 & 17.2 & $25.5(5.6)$ & 44.5 \\
\hline$\$ 72,800-\$ 129,999$ & 35.6 & $27.2(4.8)$ & 67.5 & 32.9 & $26.4(5.9)$ & 50.9 \\
\hline$\$ 52,000-\$ 72,799$ & 17.1 & $26.8(4.9)$ & 63.2 & 16.0 & $27.2(6.6)$ & 55.8 \\
\hline$\$ 41,600-\$ 51,999$ & 8.2 & $27.2(5.1)$ & 65.4 & 8.0 & $27.3(7.1)$ & 53.4 \\
\hline$\$ 26,000-\$ 41,599$ & 11.9 & $27.0(5.6)$ & 63.4 & 13.4 & $27.3(6.5)$ & 58.7 \\
\hline$\$ 0-\$ 25,999$ & 7.8 & $27.0(5.6)$ & 63.4 & 12.5 & $27.0(6.7)$ & 58.1 \\
\hline
\end{tabular}


Table 1 Socio-demographic and bodyweight characteristics of men and women: ethnicity and bodyweight analytic sample ( $n=13$ 047) (Continued)

\begin{tabular}{|c|c|c|c|c|c|}
\hline \multicolumn{6}{|l|}{ Neighbourhood Disadvantage } \\
\hline Quintile 5 (least disadvantage) & 22.0 & $26.4(4.0)$ & 61.4 & 21.2 & $25.4(5.6$ \\
\hline Quintile 4 & 22.1 & $26.8(4.7)$ & 63.8 & 22.2 & $26.3(5$. \\
\hline Quintile 3 & 19.5 & $27.5(5.3)$ & 68.2 & 20.1 & $26.7(6.3$ \\
\hline Quintile 2 & 18.9 & $27.5(5.2)$ & 68.3 & 19.3 & $27.0(6$. \\
\hline Quintile 1 (most disadvantage) & 17.5 & $27.4(5.7)$ & 64.9 & 17.2 & $28.0(7.2$ \\
\hline $\begin{array}{l}\text { Countries of birth of respondents cor } \\
\text { Oceania: New Zealand, Fiji, Papua Ne } \\
\text { North-West Europe: United Kingdom, } \\
\text { Southern \& Eastern Europe: Italy, Pola } \\
\text { North Africa \& Middle East: Lebanon, } \\
\text { South-East Asia: Philippines, Vietnam, } \\
\text { North-East Asia: China, Hong Kong, J } \\
\text { Southern \& Central Asia: India, Sri Lar } \\
\text { Americas: USA, Canada, Chile, Colom } \\
\text { Sub-Saharan Africa: South Africa, Mau }\end{array}$ & $\begin{array}{l}\% \text { of } \\
\text { ds, Gerr } \\
\text {, Feder } \\
\text { ney, Ira } \\
\text { ndones } \\
\text { Bangla }\end{array}$ & $\begin{array}{l}\text { sample } \\
\text { ublic of Yug }\end{array}$ & ania, Fo & Republi & acedonia \\
\hline
\end{tabular}

further model (model 4) adjusting for country of birth. The hypothesised least acculturated group was used as the reference category: length of residence $<5$ years, and age at arrival $\geq 25$ years. Linear and logistic regression analyses were used to model BMI and odds overweight/ obesity as per previous.

\section{Results}

\section{Ethnicity and bodyweight}

Table 1 describes the summary characteristics of the analytic sample $(n=13047)$. The majority of the sample were Australian born (76.5 and $77.4 \%$ for men and women), which is broadly reflective of their proportion in the Australian population. The majority were middle aged (35-64 years) and lived in either major cities or inner regional centres. Nearly half of the women (48.2\%) had low educational attainment. The highest proportions of overweight and obesity were seen in men and women born in Southern and Eastern Europe (74.7 and $64.5 \%$ respectively). Male and female immigrants from North Africa/Middle East had the highest mean BMIs of $28.8 \mathrm{~kg} \mathrm{~m}^{-2}$ (SD 8.5) and $28.0 \mathrm{~kg} \mathrm{~m}^{-2}$ (SD 6.2) respectively. Significant interaction effects for gender and ethnicity on BMI $(p<0.001)$, and on percent overweight/obese $(p=0.004)$ were found, therefore analyses were stratified by gender.

Among men, after adjustment for age, area remoteness, education, occupation, household income and neighbourhood disadvantage, BMI was significantly higher for immigrants from North Africa/Middle East $(\beta=1.42,95 \%$ confidence interval $(\mathrm{CI})=0.19,2.64)$ and Oceania $(\beta=0.84, \quad C I=0.16,1.52)$, compared with Australian born (Table 2). Men from North West Europe $(\beta=-0.47, C I=-0.89,-0.05)$, North East Asia $(\beta=-1.48, C I=-2.63,-0.34)$ and Southern and Central Asia $(\beta=-1.24, \mathrm{CI}=-2.17,-0.32)$ had significantly lower
BMIs relative to Australian born. In the fully adjusted models, the odds of being overweight/obese were significantly less among Asian ethnic groups.

Among women, six of the nine ethnic immigrant groups had significantly lower BMIs compared with the Australian-born reference group. The results for odds overweight/obesity showed similar patterns. Immigrants from North East Asia had the largest (lower) BMI difference compared with Australian-born $(\beta=-4.93, \mathrm{CI}=$ $-6.06,-3.79)$.

\section{Acculturation and bodyweight}

Table 3 describes the summary characteristics of the foreign born sample $(n=2997)$, which includes small proportions in the youngest age category (18-24 years) and the majority living in major cities. Over $40 \%$ of women were in the lowest category for individual measures of socioeconomic position (education and occupation). Over $75 \%$ of the foreign born sample had lived in Australia for $>15$ years and the majority arrived as adults ( $\geq 25$ years). Those who had resided in Australia for 15 or more years, had the highest BMIs in both males and females (27.3 (5.1) and 26.4 (5.8) respectively). Men who arrived during adolescence had a relatively high BMI of 28.0 (6.2) and both men and women who arrived as children (0-11 years), also had high BMIs compared with the other categories. The \%overweight/obese descriptive results for the acculturation variables showed the same patterns as for mean BMI.

Length of residence in Australia: After adjustment for age, area remoteness, education, occupation, household income, neighbourhood disadvantage and nativity, male immigrants who had lived in Australia for $\geq 15$ years had significantly higher BMIs $(\beta=1.27, \mathrm{CI}=0.10,2.44)$ compared with their counterparts residing in Australia less than 5 years (Table 4). Among female immigrants, as 


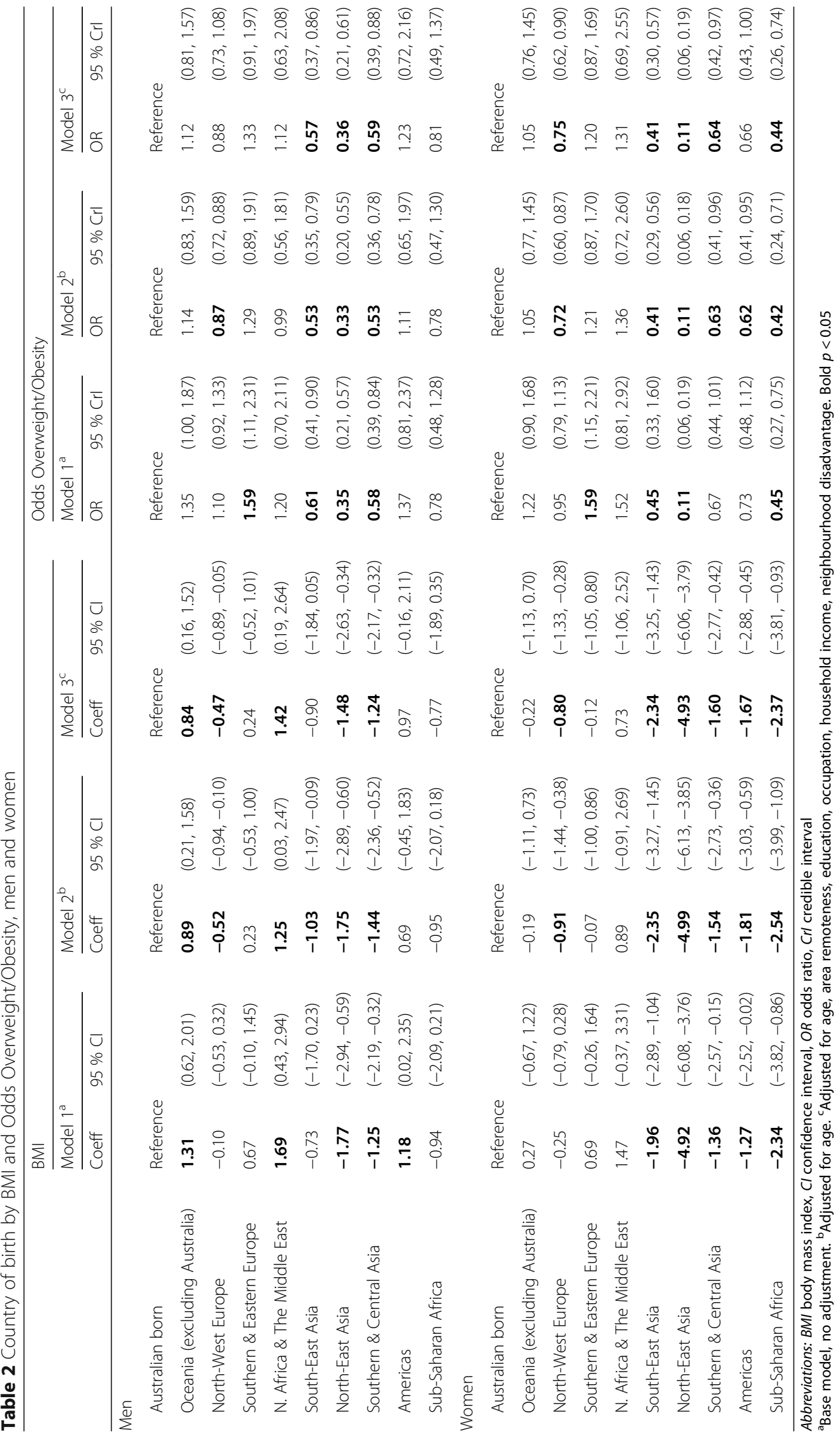


Table 3 Socio-demographic and bodyweight characteristics of men and women in the acculturation and bodyweight sample $(n=2$ 997)

\begin{tabular}{|c|c|c|c|c|c|c|}
\hline & \multicolumn{3}{|c|}{$\begin{array}{l}\text { Men (FB Only) } \\
(n=1457,48.6 \%) \\
\text { 27.1(5.2) mean BMI(SD) } \\
\text { 64.9\%Owt/Obese }\end{array}$} & \multicolumn{3}{|c|}{$\begin{array}{l}\text { Women (FB Only) } \\
(n=1540,51.4 \%) \\
25.9(6.0) \text { mean BMI(SD) } \\
47.8 \% \text { Owt/Obese }\end{array}$} \\
\hline & $\%$ & Mean BMI (SD) & $\%$ Owt/ Obese & $\%$ & Mean BMI (SD) & \%Owt/ Obese \\
\hline \multicolumn{7}{|l|}{ Length of residence in Australia } \\
\hline$<5$ years & 6.7 & $25.3(4.1)$ & 49.0 & 9.1 & $23.2(4.2)$ & 25.7 \\
\hline $5-9$ years & 6.2 & $25.8(4.6)$ & 57.1 & 5.8 & $24.9(9.0)$ & 31.5 \\
\hline 10-14 years & 7.8 & $26.7(6.2)$ & 56.6 & 9.2 & $24.7(5.2)$ & 41.1 \\
\hline$\geq 15$ years & 79.3 & $27.3(5.1)$ & 67.6 & 76.0 & $26.4(5.8)$ & 52.4 \\
\hline \multicolumn{7}{|l|}{ Age at Arrival } \\
\hline$\geq 25$ years (arrived as adult) & 44.9 & $26.7(5.1)$ & 62.6 & 45.1 & $25.5(5.8)$ & 46.2 \\
\hline 18-24 years (arrived as young adult) & 18.8 & $26.7(4.6)$ & 62.6 & 19.7 & $25.2(5.1)$ & 44.2 \\
\hline 12-17 years (arrived as an adolescent) & 8.0 & $28.0(6.2)$ & 70.1 & 9.0 & $26.2(5.5)$ & 50.0 \\
\hline 0-11 years (arrived as young child) & 28.3 & $27.5(5.3)$ & 68.5 & 26.2 & $27.0(6.8)$ & 52.5 \\
\hline \multicolumn{7}{|l|}{ Age } \\
\hline 18-24 years & 5.4 & $24.9(4.2)$ & 40.5 & 4.7 & $22.4(4.1)$ & 23.3 \\
\hline $25-34$ years & 11.9 & $25.9(4.6)$ & 50.0 & 12.3 & $23.9(5.7)$ & 28.6 \\
\hline $35-44$ years & 15.0 & $27.2(4.2)$ & 65.3 & 16.9 & $25.6(5.9)$ & 43.8 \\
\hline $45-54$ years & 22.5 & $27.3(5.0)$ & 68.9 & 21.8 & $25.7(5.8)$ & 46.7 \\
\hline $55-64$ years & 20.6 & $28.0(5.5)$ & 73.7 & 21.9 & $27.0(6.7)$ & 54.3 \\
\hline $65-74$ years & 15.5 & $27.5(5.6)$ & 69.0 & 13.8 & $27.2(5.4)$ & 60.6 \\
\hline$>75$ years & 9.0 & $26.2(4.6)$ & 61.1 & 8.6 & $26.7(4.9)$ & 62.1 \\
\hline \multicolumn{7}{|l|}{ Remoteness } \\
\hline Major City & 76.9 & $27.0(5.1)$ & 64.5 & 77.9 & $25.8(6.0)$ & 46.7 \\
\hline Inner Regional Australia & 15.8 & $27.3(5.7)$ & 64.1 & 13.9 & $26.1(5.2)$ & 51.4 \\
\hline Outer Regional Australia & 5.9 & $27.2(4.9)$ & 68.6 & 6.8 & $27.0(6.7)$ & 52.4 \\
\hline Remote and Very Remote Australia & 1.3 & $27.9(4.0)$ & 78.9 & 1.4 & $24.9(5.1)$ & 48.6 \\
\hline \multicolumn{7}{|l|}{ Highest attained education level } \\
\hline Bachelor + & 32.3 & $26.7(5.3)$ & 61.1 & 33.6 & $24.6(5.1)$ & 38.8 \\
\hline Diploma & 11.0 & $26.7(4.8)$ & 60.6 & 10.7 & $25.1(6.2)$ & 41.2 \\
\hline Certificate (trade/business) & 24.9 & $27.3(4.4)$ & 70.8 & 13.4 & $26.7(6.4)$ & 53.4 \\
\hline School - Year 12 and below & 31.8 & $27.4(5.6)$ & 65.5 & 42.3 & $26.9(6.2)$ & 54.8 \\
\hline \multicolumn{7}{|l|}{ Occupation } \\
\hline Managers and professionals & 29.2 & $26.8(4.7)$ & 65.0 & 22.5 & $25.0(4.9)$ & 40.9 \\
\hline White Collar & 12.8 & $26.9(5.5)$ & 61.5 & 23.6 & $25.4(6.1)$ & 41.8 \\
\hline Blue Collar & 25.0 & $27.3(4.8)$ & 65.1 & 7.3 & $26.0(6.5)$ & 42.9 \\
\hline Unemp/Not in Labour Force & 32.9 & $27.2(5.7)$ & 65.8 & 46.6 & $26.5(6.2)$ & 54.9 \\
\hline \multicolumn{7}{|l|}{ Household Income } \\
\hline$>\$ 130,000$ k per annum & 18.3 & $26.8(4.4)$ & 61.3 & 15.7 & $24.7(5.4)$ & 38.4 \\
\hline$\$ 72,800-\$ 129,999$ & 35.4 & $27.4(5.2)$ & 68.6 & 33.1 & $25.6(5.5)$ & 46.9 \\
\hline$\$ 52,000-\$ 72,799$ & 16.3 & $26.2(4.5)$ & 58.6 & 15.9 & $25.8(6.3)$ & 43.3 \\
\hline$\$ 41,600-\$ 51,999$ & 7.6 & $27.1(5.7)$ & 63.1 & 7.5 & $25.9(5.4)$ & 44.8 \\
\hline$\$ 26,000-\$ 41,599$ & 14.1 & $27.6(6.1)$ & 68.0 & 14.3 & $26.8(6.7)$ & 55.4 \\
\hline$\$ 0-\$ 25,999$ & 8.3 & $27.0(5.4)$ & 65.3 & 13.4 & $27.0(6.4)$ & 59.9 \\
\hline
\end{tabular}


Table 3 Socio-demographic and bodyweight characteristics of men and women in the acculturation and bodyweight sample $(n=2$ 997) (Continued)

\begin{tabular}{lllllll}
\hline Neighbourhood Disadvantage & & & & & \\
Quintile 5 (least disadvantage) & 24.8 & $26.5(3.7)$ & 62.7 & 23.6 & $24.3(4.7)$ & 36.1 \\
Quintile 4 & 20.4 & $26.7(4.8)$ & 63.8 & 21.3 & $25.8(5.4)$ & 48.2 \\
Quintile 3 & 16.7 & $28.0(6.3)$ & 68.7 & 18.1 & $26.1(6.5)$ & 48.2 \\
Quintile 2 & 20.0 & $27.5(5.7)$ & 70.8 & 19.5 & $25.9(5.9)$ & 48.2 \\
Quintile 1 (most disadvantage) & 18.0 & $26.8(5.4)$ & 58.9 & 17.5 & $27.8(7.0)$ & 62.2 \\
\hline
\end{tabular}

Abbreviations: $B M I$ body mass index, $F B$ foreign born, Owt overweight, SD standard deviation

length of residence increased, so too did odds of overweight/obesity, however the relationship reached significance only for those living in Australia for $\geq 15$ years (odds ratio $(\mathrm{OR})=1.59,95 \%$ credible interval $(\mathrm{CrI})=$ $1.04,2.46)$. Odds ratios were not significant for men and BMI results were not significant for women.

\section{Age at arrival}

After full adjustment, male immigrants who arrived as a young child or an adolescent had significantly higher BMIs $(\beta=1.27, C I=0.59,1.95$ and $\beta=2.01, C I=1.03$, 3.06 respectively) and odds overweight/obesity $(\mathrm{OR}=$ $1.65, \mathrm{CrI}=1.26,2.16$ and $\mathrm{OR}=2.09, \mathrm{CrI}=1.38,3.18$ respectively) compared with immigrants who arrived as adults (Table 5). Among women, immigrants who arrived as a young child also had significantly higher BMIs $(\beta=1.67, C I=0.92,2.42)$ and odds overweight/obesity $(\mathrm{OR}=1.45, \mathrm{CrI}=1.12,1.86)$ compared with those who arrived as adults.

\section{Discussion}

This study revealed gender-specific ethnic differences in bodyweight in a national sample of Australian adults. Adjustment for socioeconomic factors had minimal and variable impact on regression coefficients and odds ratios, suggesting that these constructs do not explain ethnic differences in bodyweight in Australia. Two ethnic groups had significantly higher BMI compared with Australian born - male immigrants born in North Africa/ Middle East, and Oceania. This contrasts to results from single-State Australian studies, which identified immigrants born in Southern European countries as having significantly higher BMIs compared with Australian born after full adjustment [23, 24]. Published results from these earlier studies were not stratified by gender and comparisons are difficult due to methodological constraints (as described in the introduction). There is a paucity of international studies focused on immigrants from Oceania and North Africa/Middle Eastern regions. International prevalence data has shown in excess of $50 \%$ obesity rates in countries of these regions [1], however it cannot be assumed that nationals living in their own countries have the same characteristics as those who immigrate, underscoring the importance of further research on ethnic differences in bodyweight among existing and emerging immigrant cohorts.

Findings from this study of lower BMI among male and female Asian immigrants compared with Australian born are generally consistent with State-based research $[23,24]$. It remains important however, to include Asian immigrants in obesity monitoring and prevention efforts, as using Asian BMI cut-offs for overweight/obesity has revealed higher levels of health risks, [25] and generational studies from multiple countries have shown a rapid upward assimilation of Asian immigrants' BMI to the host country's BMI over the course of one generation [14, 24, 53].

The acculturation results demonstrated that Australian immigrants are no exception to international evidence of immigrants having lower BMI on arrival and increasing BMI with longer durations of residence. A number of contributing factors have been postulated to explain these phenomena. These include, strict immigrant health entry requirements [54]; protective biological, behavioural and sociocultural factors [54, 55]; and immigrant self-selection, that is, only those who are healthy, educated and have the financial means to migrate, do so [56]. Most studies from developed countries found that women are particularly susceptible to increasing BMI with longer duration of residence [28, 29, 57, 58], although others have found the opposite [28]. The modelling in this study showed that the relationship between duration of residence and BMI was significant only for men living in Australia for $\geq 15$ years and that among women, socioeconomic factors and nativity explained the increased BMI with increased length of residence. The odds of overweight/obesity remained significantly higher after full adjustment among female immigrants residing in Australia $\geq 15$ years, which suggests that conclusions on gender acculturation differences may vary depending on the measures used to assess adiposity.

Age at arrival results from this study supported the length of residence results which in turn is consistent with findings that arrival $<20$ years of age (compared with arrival at later ages), placed immigrants at higher risk of overweight/obesity [40]. This study is unique in 


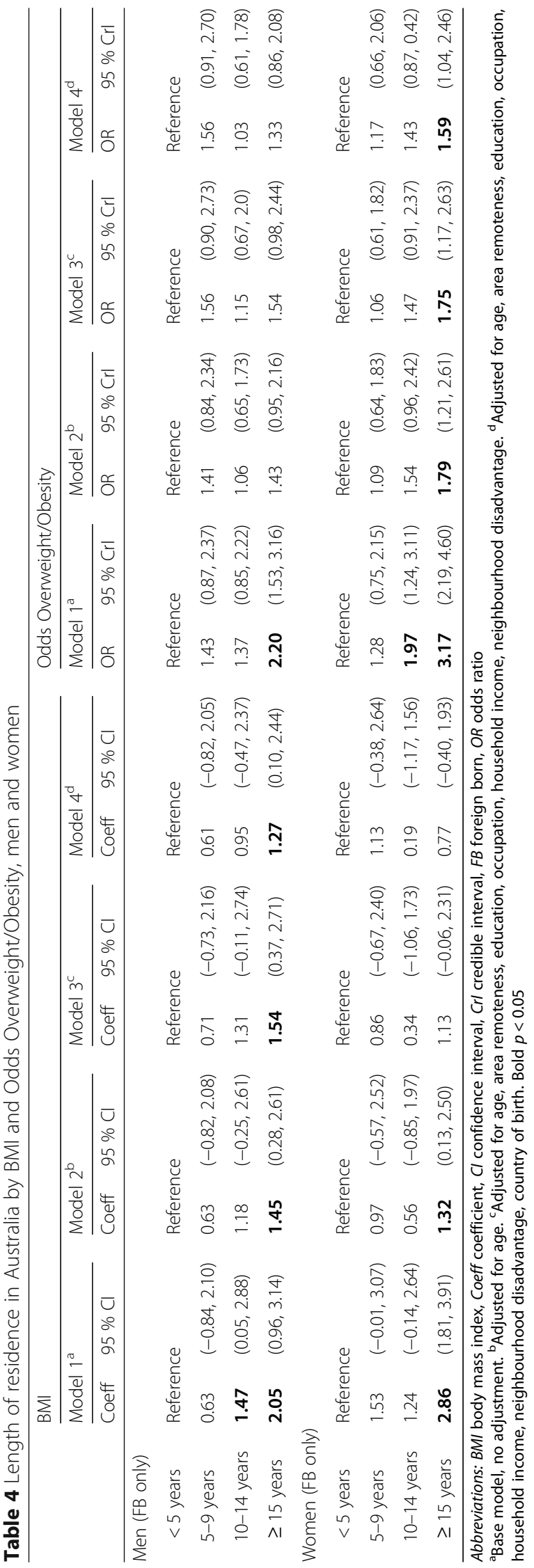




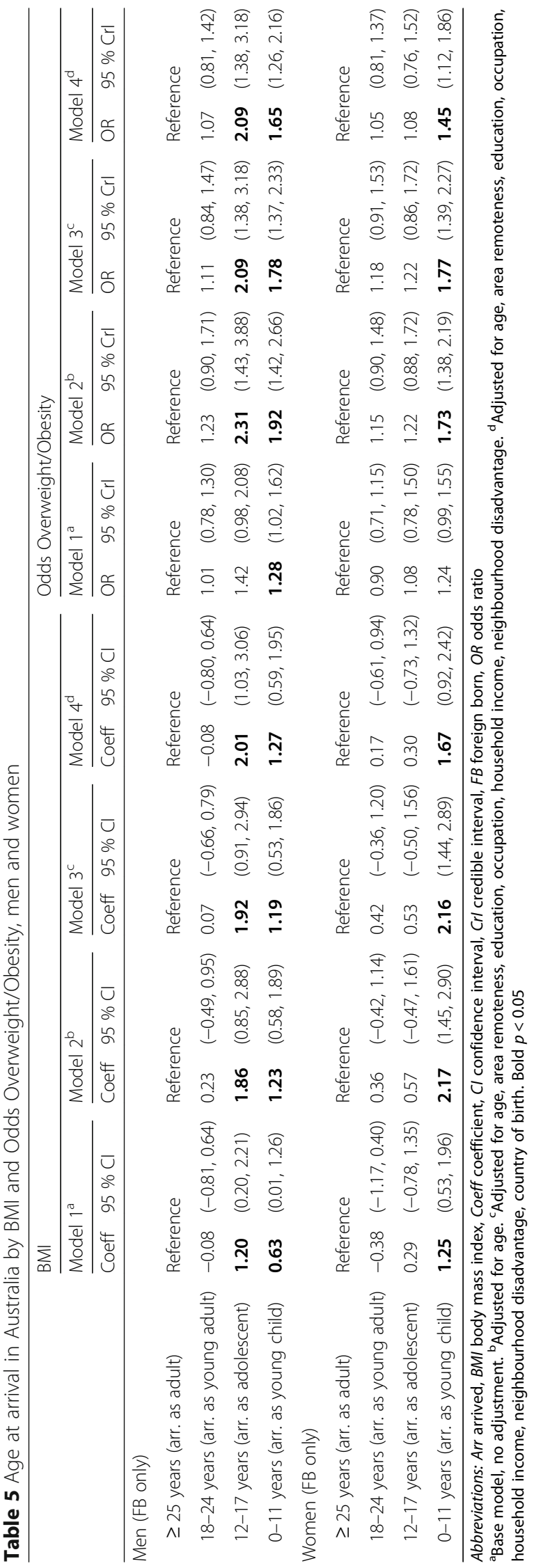


showing that men who arrived as adolescents are at particularly high risk in terms of their adult BMI and likelihood of overweight/obesity, suggesting an important area for policy attention.

\section{Strengths, limitations and areas for further research}

This study had a number of limitations. Country of birth is the most commonly used indicator of ethnicity in Australian datasets and other, more sensitive measures such as self-identified ethnicity [59] are not routinely gathered. Country of birth may be only one of several factors which influence a person's ethnicity [60] and in this study, aggregating countries into regions may mask important heterogeneity both within countries and within regions. The self-completed questionnaire was only available in English and analysis of reasons for exclusion, revealed that birth in non-English speaking regions may be an important predictor of questionnaire non-return and may have introduced selection bias into the sample. Self-reported BMI is known to be subject to error [61] and further research is needed to confirm the presence and direction of weight-reporting biases among adults in different ethnic groups [28, 62]. In this study, as we were comparing ethnic differences in overweight and obesity relative to Australian born, the WHO standard overweight and obesity cut-off points were used. This may underestimate overweight and obesity amongst some Asian ethnic groups [63].

Acknowledging the constraints of this paper, the complexity of ethnicity as a construct and the underrepresentation of ethnic minority groups in health research, we echo the calls of other researchers [54, 59] for increased population-level research on migrant health trends and the inclusion of a greater range of ethnicity variables and appropriate data collection techniques to enable this to occur. Findings from this study, along with research from other developed countries, suggest that the complex and intertwining nature of ethnicity, acculturation, gender and socioeconomic status requires further context specific research. In particular longitudinal studies will build on our findings and reveal trends which take into account cohort effects and secular and age-related increases in obesity [64].

\section{Conclusions}

This paper was the first study of its kind to examine ethnic differences in BMI and overweight/obesity and the influence of acculturation on the bodyweight of immigrants in a national sample of Australian adults. Our findings emphasise the importance of targeted and tailored obesity prevention intervention aimed at ethnic groups at high risk of overweight and obesity. In the Australian context this includes male immigrants from North Africa/Middle East and Oceania regions. Our findings also highlight the need for public health policy directed at immigrants in the early years post-arrival and to those who arrive as young children or adolescents, in order to combat acculturation-related weight gain. The study adds to the international literature by demonstrating the pervasiveness of ethnic differences in immigrant bodyweight and the consistency and speed of immigrant acculturation to a country's unhealthy weight profile in the face of obesogenic environments present in developed countries.

\section{Acknowledgements}

This paper uses unit record data from the Household, Income and Labour Dynamics in Australia (HILDA) Survey. The HILDA Project was initiated and is funded by the Australian Government Department of Social Services (DSS) (formerly FaHCSIA), and is managed by the Melbourne Institute of Applied Economic and Social Research (Melbourne Institute). The findings and views reported in this paper, however, are those of the author and should not be attributed to either DSS or the Melbourne Institute.

\section{Funding}

GT is supported by an Australian National Health and Medical Research Council Senior Research Fellowship (ID 1003710).

\section{Availability of data and materials}

The data that support the findings of this study are available from the Melbourne Institute of Applied Economic and Social Research but restrictions apply to the availability of these data which were used under license for the current study, and so are not publicly available. Those interested in accessing the data must contact the Melbourne Institute of Applied Economic and Social Research, Level 5, Business and Economics Building, 111 Barry Street, The University of Melbourne, VIC 3010, Australia, Email hildainquiries@unimelb.edu.au.

\section{Author's contributions}

GT and KM initiated the study. KM conducted the data analysis and drafted the manuscript with GT and AN providing advice, critical comments and editing of the draft. All authors read and approved the final manuscript.

\section{Competing interests}

The authors declare that they have no competing interests.

\section{Consent for publication}

Not applicable.

Ethics approval and consent to participate

This study has human research ethics approval from the QUT University Human Research Ethics Committee as a Negligible-Low Risk Category. Approval number: 1500000836.

\section{Author details}

${ }^{1}$ School of Public Health and Social Work, Queensland University of Technology (QUT), Victoria Park Road, Kelvin Grove, QLD 4059, Australia. ${ }^{2}$ Institute for Health \& Ageing, Australian Catholic University (ACU), Level 6, 215 Spring Street, Melbourne, VIC 3000, Australia.

Received: 25 February 2016 Accepted: 29 August 2016

Published online: 05 September 2016

\section{References}

1. Ng M, Fleming T, Robinson M, Thomson B, Graetz N, Margono C, et al. Global, regional, and national prevalence of overweight and obesity in children and adults during 1980-2013: a systematic analysis for the Global Burden of Disease Study 2013. Lancet. 2014;384:766-81. http://dx.doi.org/10.1016/S0140-6736(14)60460-8.

2. United Nations Department of Economic and Social Affairs Population Division. Trends in International Migration, 2015. In: Population Facts. vol. 2015/4: United Nations; 2015: 1-4. 
3. Kumar BN, Meyer HE, Wandel M, Dalen I, Holmboe-Ottesen G. Ethnic differences in obesity among immigrants from developing countries, in Oslo. Norway Int J Obes. 2006;30(4):684-90. doi:10.1038/sj.ijo.0803051;

4. Wang Y, Beydoun MA. The obesity epidemic in the United States - gender age, socioeconomic, racial/ethnic, and geographic characteristics: a systematic review and meta-regression analysis. Epidemiol Rev. 2007;29(1): 6-28. doi:10.1093/epirev/mxm007.

5. McDonald JT, Kennedy S. Is migration to Canada associated with unhealthy weight gain? Overweight and obesity among Canada's immigrants. Soc Sci Med. 2005:61(12):2469-81. doi:10.1016/j.socscimed.2005.05.004.

6. El-Sayed A, Scarborough P, Galea S. Ethnic inequalities in obesity among children and adults in the UK: a systematic review of the literature. Obes Rev. 2011;12(5):e516-34. doi:10.1111/j.1467-789X.2010.00829.x.

7. El-Sayed A, Scarborough P, Galea S. Unevenly distributed: a systematic review of the health literature about socioeconomic inequalities in adult obesity in the United Kingdom. BMC Public Health. 2012;12(1):18. doi:10. 1186/1471-2458-12-18.

8. Gearon E, Backholer K, Stevenson C, Magliano DJ, Keating C, Ball K, et al. Trends in body mass index according to educational attainment for urban Australian adults between 1980 and 2007. Int J Obes. 2015;39(6):1019-26. doi:10.1038/ijo.2015.27

9. McLaren L. Socioeconomic status and obesity. Epidemiol Rev. 2007;29(1):2948. doi:10.1093/epirev/mxm001.

10. Ball K, Crawford D. Socioeconomic status and weight change in adults: a review. Soc Sci Med. 2005;60(9):1987-2010. doi:10.1016/j.socscimed.2004.08.056.

11. Flegal KM, Carroll MD, Kit BK, Ogden CL. Prevalence of obesity and trends in the distribution of body mass index among US adults, 1999-2010. JAMA. 2012;307(5):491-7. doi:10.1001/jama.2012.39.

12. Krueger PM, Coleman-Minahan K, Rooks RN. Race/ethnicity, nativity and trends in BMI among US adults. Obesity. 2014;22(7):1739-46. doi:10.1002/oby.20744

13. Zilanawala A, Davis-Kean P, Nazroo JY, Sacker A, Simonton S, Kelly YJ. Race/ ethnic disparities in early childhood BMl, obesity and overweight in the United Kingdom and United States. Int J Obes. 2014;39:520-9. doi:10.1038/ijo.2014.171.

14. Smith NR, Kelly YJ, Nazroo JY. The effects of acculturation on obesity rates in ethnic minorities in England: evidence from the Health Survey for England. Eur J Public Health. 2012;22(4):508-13. doi:10.1093/eurpub/ckr070.

15. Alkerwi AA, Sauvageot N, Pagny S, Beissel J, Delagardelle C, Lair M-L. Acculturation, immigration status and cardiovascular risk factors among Portuguese immigrants to Luxembourg: findings from ORISCAV-LUX study. BMC Public Health. 2012;12(1):1-10. doi:10.1186/1471-2458-12-864.

16. Australian Bureau of Statistics: Australian Health Survey: first results, 2011-12. 2012. http://www.ausstats.abs.gov.au/ausstats/subscriber.nsf/0/ 1680ECA402368CCFCA257AC90015AA4E/\$File/4364.0.55.001.pdf. Accessed 19 Aug 2015.

17. Australian Bureau of Statistics: Australia's population by country of birth. 2012. http://www.abs.gov.au/ausstats/abs@.nsf/Products/ 84074889D69E738CCA257A5A00120A69?opendocument. Accessed 19 Aug 2015

18. United States Census Bureau: Statistical Abstract of the United States: 2012. http:// www.census.gov/library/publications/2011/compendia/statab/131ed.html. Accessed 5 Sept 2015

19. Achat HM, Stubbs JM. Socio-economic and ethnic differences in the prevalence of overweight and obesity among school children. J Paediatr Child Health. 2012;50:E77-84. doi:10.1111/j.1440-1754.2012.02474.x.

20. Hardy LL, King L, Hector D, Baur LA. Socio-cultural differences in Australian primary school children's weight and weight-related behaviours. J Paediatr Child Health. 2013;49(8):641-8. doi:10.1111/jpc.12263.

21. O'Dea JA. Gender, ethnicity, culture and social class influences on childhood obesity among Australian schoolchildren: implications for treatment, prevention and community education. Health Soc Care Community. 2008; 16(3):282-90. doi:10.1111/j.1365-2524.2008.00768.x

22. Waters E, Ashbolt R, Gibbs L, Booth M, Magarey A, Gold L, et al. Double disadvantage: the influence of ethnicity over socioeconomic position on childhood overweight and obesity: findings from an inner urban population of primary school children. Int J Pediatr Obes. 2008;3(4):196-204. doi:10.1080/17477160802141846.

23. Astell-Burt T, Feng $X$, Croteau K, Kolt GS. Influence of neighbourhood ethnic density, diet and physical activity on ethnic differences in weight status: a study of 214,807 adults in Australia. Soc Sci Med. 2013;93:70-7. doi:10.1016/j.socscimed.2013.06.006.

24. Hauck K, Hollingsworth B, Morgan L. BMI differences in 1st and 2nd generation immigrants of Asian and European origin to Australia. Health \& Place. 2011;17(1):78-85. doi:10.1016/j.healthplace.2010.08.016.

25. Guo S, Lucas RM, Joshy G, Banks E. Cardiovascular disease risk factor profiles of 263,356 older Australians according to region of birth and acculturation, with a focus on migrants born in Asia. PLoS One. 2015;10(2), e0115627. doi:10.1371/journal.pone.0115627.

26. Redfield R, Linton R, Herskovits MJ. Memorandum for the study of acculturation. Am Anthropol. 1936;38(1):149-52.

27. Schwartz SJ, Unger JB, Zamboanga BL, Szapocznik J. Rethinking the concept of acculturation: implications for theory and research. Am Psychol. 2010; 65(4):237-51. doi:10.1037/a0019330.

28. Sanchez-Vaznaugh EV, Kawachi I, Subramanian S, Sánchez BN, AcevedoGarcia D. Differential effect of birthplace and length of residence on body mass index (BMI) by education, gender and race/ethnicity. Soc Sci Med. 2008;67(8):1300-10. doi:10.1016/j.socscimed.2008.06.015.

29. Barcenas CH, Wilkinson AV, Strom SS, Cao Y, Saunders KC, Mahabir S, et al, Birthplace, years of residence in the United States, and obesity among Mexican-American adults. Obesity. 2007;15(4):1043-52.

30. Albrecht SS, Diez-Roux AV, Aiello AE, Schulz AJ, Abraido-Lanza AF. Secular trends in the association between nativity/length of US residence with body mass index and waist circumference among Mexican-Americans, 1988-2008. Int J Public Health. 2013;58(4):573-81. doi:10.1007/s00038-012-0414-5.

31. Bennett GG, Wolin KY, Askew S, Fletcher R, Emmons KM. Immigration and obesity among lower income blacks. Obesity. 2007;15(6):1391-4.

32. Delavari M, Sønderlund AL, Swinburn B, Mellor D, Renzaho AMN. Acculturation and obesity among migrant populations in high income countries: a systematic review. BMC Public Health. 2013;13(1):458. doi:10. 1186/1471-2458-13-458.

33. Oza-Frank R, Cunningham SA. The weight of US residence among immigrants: a systematic review. Obes Rev. 2010;11(4):271-80. doi:10.1111/j. 1467-789X.2009.00610.X.

34. Salant T, Lauderdale DS. Measuring culture: a critical review of acculturation and health in Asian immigrant populations. Soc Sci Med. 2003:57(1):71-90. doi:10.1016/S0277-9536(02)00300-3.

35. Wan-Ping L, Lingard J, Bermingham M. Change in diet and body mass index in Taiwanese women with length of residence in Australia. Asia Pac J Clin Nutr. 2007;16(1):56-65.

36. Albrecht SS, Osypuk TL, Kandula NR, Gallo LC, Lê-Scherban F, Shrager S, et al. Change in waist circumference with longer time in the United States among Hispanic and Chinese immigrants: the modifying role of the neighborhood built environment. Ann Epidemiol. 2015;25(10):767-72. http://dx.doi.org/10.1016/j.annepidem.2015.07.003.

37. Ro A, Bostean G. Duration of U.S. stay and body mass index among Latino and Asian immigrants: a test of theoretical pathways. Soc Sci Med. 2015;144 39-47. doi:10.1016/j.socscimed.2015.09.001.

38. Gray L, Harding S, Reid A. Evidence of divergence with duration of residence in circulatory disease mortality in migrants to Australia. Eur J Public Health. 2007;17(6):550-4. doi:10.1093/eurpub/ckm008.

39. Guven C, Islam A. Age at migration, language proficiency and socioeconomic outcomes: evidence from Australia. In: Discussion Paper 18/13. Melbourne: Department of Economics, Monash University; 2013.

40. Roshania R, Narayan K, Oza-Frank R. Age at arrival and risk of obesity among US immigrants. Obesity. 2008;16(12):2669-75. doi:10.1038/oby.2008.425.

41. Watson N, Wooden M. The Household, Income and Labour Dynamics in Australia (HILDA) survey: wave 1 survey methodology. 2002. http://www. melbourneinstitute.com/downloads/hilda/Bibliography/HILDA_Technical_ Papers/htec102.pdf. Accessed 26 Apr 2015

42. Watson N. Methodology for the HILDA top-up Sample. 2011. http://www. melbourneinstitute.com/hilda/biblio/HILDA_technical_papers.html. Accessed 22 Jul 2016.

43. Watson N. Longitudinal and Cross-Sectional Weighting Methodology for the HILDA Survey. 2012. http://www.melbourneinstitute.com/hilda/biblio/ HILDA_technical_papers.html. Accessed 22 Jul 2016.

44. Wooden M, Watson N, Agius P, Friedin S. Assessing the quality of the height and weight data in the HILDA survey. 2008. http://www. melbourneinstitute.com/hilda/biblio/HILDA_technical_papers.html. Accessed 24 Aug 2015. 
45. World Health Organisation: Global database on body mass index. 2013. http://apps.who.int/bmi/index.jsp?introPage=intro_3.html. Accessed 19 Jul 2015.

46. Australian Bureau of Statistics: Standard Australian Classification of Countries (SACC). 2011. http://www.abs.gov.au/ausstats/abs@.nsf/mf/1269.0. Accessed 21 Apr 2015.

47. Australian Bureau of Statistics: Socio-Economic Indexes for Areas. 2013. http://www.abs.gov.au/websitedbs/censushome.nsf/home/ seifa?opendocument\&navpos=260. Accessed 22 July 2016.

48. Australian Bureau of Statistics: Australian Standard Geographical Classification (ASGC). 2001. http://www.abs.gov.au/AUSSTATS/abs@.nsf/ DetailsPage/1216.02001?OpenDocument. Accessed 21 Apr 2015.

49. Cleland V, Hume C, Crawford D, Timperio A, Hesketh K, Baur LA, et al. Urban-rural comparison of weight status among women and children living in socioeconomically disadvantaged neighbourhoods. Med J Aust. 2010; 192(3):137.

50. Lau R, Morse CA. Health and wellbeing of older people in Anglo-Australian and Italian-Australian communities: a rural-urban comparison. Aust J Rural Health. 2008;16(1):5-11.

51. Browne WJ. MCMC Estimation in MLwiN Version 2.13. United Kingdom: Centre for Multilevel Modelling, University of Bristol; 2009.

52. Leckie G, Charlton C. Runmlwin-a program to run the MLwiN multilevel modelling software from within Stata. J Stat Softw. 2013;52(11):1-40.

53. Bates LM, Acevedo-Garcia D, Alegria M, Krieger N. Immigration and generational trends in body mass index and obesity in the United States: results of the National Latino and Asian American Survey, 2002-2003. Am J Public Health. 2008;98(1):70-7. doi:10.2105/AJPH.2006.102814.

54. Anikeeva O, Bi P, Hiller JE, Ryan P, Roder D, Han G-S. The health status of migrants in Australia: a review. Asia Pac J Public Health. 2010;22(2):159-93. doi:10.1177/1010539509358193.

55. Krueger $P$, Reither E. Mind the gap: race/ethnic and socioeconomic disparities in obesity. Current Diabetes Reports. 2015;15(11):1-9. doi:10.1007/s11892-015-0666-6.

56. Kennedy S, McDonald JT, Biddle N. The healthy immigrant effect and immigrant selection: evidence from four countries. In: SEDAP Research Paper \#164. Ottawa: Social and Economic Dimensions of an Ageing Population (SEDAP) Research Program; 2006.

57. Antecol H, Bedard K. Unhealthy assimilation: why do immigrants converge to American health status levels? Demography. 2006;43(2):337-60. doi:10.1353/dem.2006.0011.

58. Kaplan MS, Huguet N, Newsom JT, McFarland BH. The association between length of residence and obesity among Hispanic immigrants. Am J Prev Med. 2004;27(4):323-6. doi:10.1016/j.amepre.2004.07.005.

59. Abouzeid M, Bhopal RS, Dunbar JA, Janus ED. The potential for measuring ethnicity and health in a multicultural milieu: the case of type 2 diabetes in Australia. Ethn Health. 2013;19(4):424-39. doi:10.1080/13557858.2013.828828.

60. Ford CL, Harawa NT. A new conceptualization of ethnicity for social epidemiologic and health equity research. Soc Sci Med. 2010;71(2):251-8. doi:10.1016/j.socscimed.2010.04.008.

61. Gorber SC, Tremblay MS, Moher D, Gorber B. A comparison of direct vs. selfreport measures for assessing height, weight and body mass index: a systematic review. Obes Rev. 2007;8(4):307-26. doi:10.1111/j.1467-789X.2007. 00347.x.

62. Richmond TK, Thurston I, Sonneville K, Milliren CE, Walls CE, Austin SB. Racial/ethnic differences in accuracy of body mass index reporting in a diverse cohort of young adults. Int J Obes. 2015;39(3):546-8. doi:10.1038/ijo.2014.147.

63. Stella SY, Kwon SC, Wyatt L, Islam N, Trinh-Shevrin C. Weighing in on the hidden Asian American obesity epidemic. Prev Med. 2015;73:6-9. http://dx.doi.org/10.1016/j.ypmed.2015.01.007.

64. Albrecht SS, Roux AVD, Kandula NR, Osypuk TL, Ni H, Shrager S. Immigrant assimilation and BMI and waist size: a longitudinal examination among hispanic and chinese participants in the multi-ethnic study of atherosclerosis. Obesity. 2013;21(8):1695-703. doi:10.1002/oby.20104.

\section{Submit your next manuscript to BioMed Central and we will help you at every step:}

- We accept pre-submission inquiries

- Our selector tool helps you to find the most relevant journal

- We provide round the clock customer support

- Convenient online submission

- Thorough peer review

- Inclusion in PubMed and all major indexing services

- Maximum visibility for your research

Submit your manuscript at www.biomedcentral.com/submit
Biomed Central 